\title{
COVID-19 and Drug Shortages: A Call to Action
}

\author{
Andrew G. Shuman, MD, FACS; Erin R. Fox, PharmD, BCPS, FASHP; and Yoram Unguru, MD, MS, MA
}

\begin{abstract}
SUMMARY
The ever-vulnerable medication supply chain is being further strained by the COVID-19 pandemic. Pharmacists in all settings, including managed care, will need to prepare for a potential exacerbation of existing and new drug shortages in the midst of unprecedented crisis. We summarize the major issues, discuss potential mitigation strategies, and call on our colleagues to respond with the resilience necessary to protect our patients.
\end{abstract}

J Manag Care Spec Pharm. 2020;26(8):945-47

Copyright $\odot 2020$, Academy of Managed Care Pharmacy. All rights reserved.

$\mathrm{I}$ n early 2020, as pharmacists watched the novel SARS-CoV-2 virus close down portions of China, medication shortages were top of mind. Shortages were a particular concern, since the global supply chain is overly reliant on precursor chemicals and active pharmaceutical ingredients from China (and, to a lesser degree, India). ${ }^{1}$ Interest in specific lists of products that relied on components from China was strong; however, most pharmaceutical companies decline to name their sources, and public transparency is not a legal requirement. Despite concern for shortages linked to manufacturing closures in China, only 1 drug shortage was specifically attributed to this cause. The U.S. Food and Drug Administration could not name the specific product but did note alternatives were available. ${ }^{2}$

As the virus made its way to the United States, some pharmacists reportedly began stockpiling medications needed for a surge of critically ill patients, specifically sedatives, opioids, and paralytics. Media hype regarding yet-to-be-proven treatments, such as hydroxychloroquine, also prompted pharmacies to purchase additional supplies. Because of concerns about aerosol-generating procedures, health systems that normally used albuterol-nebulized treatments suddenly needed large amounts of albuterol-metered dose inhalers. Most of all, the sudden surge in the number of critically ill and ventilated patients required much larger amounts of propofol, midazolam, fentanyl, rocuronium, and cisatracurium. Each of these factors contributed to scarcity of essential, lifesaving medications.

The current situation highlights the fragility of a medication supply chain that relies on just-in-time manufacturing at factories already at capacity. Shortages of essential medications have plagued patients and clinicians long before the COVID-19 pandemic, including many required to manage critically ill ventilated patients. ${ }^{1}$ However, the current health care crisis has deracinated all aspects of routine clinical management. ${ }^{3}$ Because of disrupted supply/delivery chains and increased demand, the potential effect on drug delivery and access is similarly devastating. ${ }^{4}$ The unavailability of lifesaving medications spares no one, threatening inpatients and outpatients, including those with and without COVID-19. ${ }^{4}$

Stakeholders within pharmaceutical delivery are keenly aware of the negative effect that ongoing drug shortages have for patients and the increased costs for health systems. ${ }^{1,5,6}$ Despite legislative attention and ongoing federal, state and local efforts, ${ }^{7,8}$ the underlying fundamental causes are exacerbated by the current crisis. Further, none of the recommendations provided by the interagency Drug Shortage Task Force in October 2019 have been implemented. ${ }^{1}$ We call on our pharmacists and managed care colleagues to prepare and work to mitigate the potential critical drug shortages related to COVID-19 that could overwhelm an already strained system. ${ }^{9}$

\section{Supply Chain Ethical Dilemmas}

Faced with a pandemic, the needs of populations must be considered and contextualized over and above individual patient-level requirements. ${ }^{10}$ However, for the bedside clinician whose sole focus is the individual patient, the needs of the population can be contradictory to the obligations of beneficence, fidelity, and the duty to care. The way in which selected scarce resources are allocated is neither natural nor necessarily self-evident to frontline clinicians. ${ }^{11}$ This shift from the traditional patient-physician ethic towards a public health ethic relates to epidemiological concerns and the need to flatten the curve, prioritization by urgency/severity, and concerns regarding available resources. Thus, proactive conservation of drugs at risk for shortage is responsible and, in fact, obligatory.

The way to accomplish proactive conservation is to ensure appropriate use. For example, patients with a prescription for an inhaler filled once in the past 2 years may not need an immediate refill at this time. When supplies are short, before filling a scarce medication, pharmacists should maintain open lines of communication and consult with the patient and provider. Managed care companies should review policies and consider where changes could be made to preserve supply. To reduce waste of critically short items in surgical and procedure areas, pharmacists can also work with providers to round-down doses. In collaboration with their pharmacy colleagues, clinicians should review overall supplies of firstline agents and, when possible, work to use alternatives with better inventory.12-14 Although a full description of the available frameworks for managing shortages is beyond the scope of this commentary, perhaps the single most important principle is direct, open, and collaborative communication strategies by 
all stakeholders, from supply procurement to dispensing in all settings. ${ }^{13,14}$

\section{Role of the Pharmacist}

Drug shortages have historically strained workflow and required inordinately more time and effort to procure and distribute critical drugs. ${ }^{15}$ Despite incremental increases in demand for scarce products, including medications, the current pandemic will invariably alter the structure and makeup of the workforce, since staffing shortages may also be present. Pharmacists must work not only to keep pace with the increased medication needs, but must also engage with clinicians to identify and provide reasonable alternatives. Online resources for monitoring and responding to drug shortages can assist with these tasks. ${ }^{16,17}$

Pharmacists should work with their organizations to provide specific guidance for use as specific shortages arise. For example, pharmacists should sequester supplies of hydroxychloroquine and other established medications that remain of unproven benefit against COVID-19 for patients who have been taking them for clear indications before the pandemic. ${ }^{18}$ In addition, pharmacists should consider refusing to fill hydroxychloroquine prescriptions written for family, friends, or self from providers interested in keeping a supply on hand "just in case." A supply of hydroxychloroquine and other putative COVID-19 treatments could also be reserved for clinical trials. These actions ensure the most appropriate use of a drug in potentially limited supply. Such actions by pharmacists will require buy-in from all stakeholders, including patients, physicians, insurers, and policymakers. Managed care organizations should work closely with their internal and network pharmacists to customize policies and protect the supply chain.

\section{Conclusions}

The consequences of COVID-19 on the health care marketplace continue to ripple and evolve. The susceptible pharmaceutical supply chain, and patients, stand to suffer greatly. Stakeholders must summon the fortitude to safeguard supply, consolidate manpower, and thoughtfully approach financial hurdles for us to collectively bolster a vulnerable system and support those whose lives depend on us to provide the medications they require. Pharmacists can take the following immediate actions to ameliorate not only the current crisis, but also address future challenges: (a) advocate for implementation of the interagency Drug Shortage Task Force recommendations, in particular, a quality rating scale ${ }^{1}$; (b) participate in your organization's drug shortage task force or scarce rationing committee to provide frontline insight and recommendations for alternatives and management strategies; and (c) stay up to date on the most current drug shortage information.

\section{Authors}

ANDREW G. SHUMAN, MD, FACS, Center for Bioethics and Social Sciences in Medicine and Michigan Institute for Clinical and Health Research, University of Michigan Medical School, Ann Arbor. ERIN R. FOX, PharmD, BCPS, FASHP, Department of Pharmacy, University of Utah Health, Salt Lake City. YORAM UNGURU, MD, MS, MA, Division of Pediatric Hematology/Oncology, The Herman and Walter Samuelson Children's Hospital at Sinai, Baltimore, Maryland, and Berman Institute of Bioethics, Johns Hopkins University, Baltimore, Maryland.

AUTHOR CORRESPONDENCE: Erin R. Fox, PharmD, BCPS, FASHP, Drug Information and Support Services, Department of Pharmacy, University of Utah Health, 50 N. Medical Dr., A050, Salt Lake City, UT 84132. Tel.: 801.587.3621;

Email:Erin.Fox@hsc.utah.edu.

\section{DISCLOSURES}

The authors declare no funding sources nor conflicts of interest.

\section{REFERENCES}

1. U.S. Food and Drug Administration. Drug shortages: root causes and potential solutions. 2019. Available at: https://www.fda.gov/media/131130/ download. Accessed June 10, 2020.

2. U.S. Food and Drug Administration. Coronavirus (COVID-19) supply chain update. February 27, 2020. Available at: https://www.fda.gov/newsevents/press-announcements/coronavirus-covid-19-supply-chain-update. Accessed June 10, 2020.

3. Parodi SM, Liu VX. From containment to mitigation of COVID-19 in the U.S. JAMA. March 13, 2020. Online ahead of print. Available at: https://jamanetwork.com/journals/jama/fullarticle/2763187. Accessed June 10, 2020.

4. Alexander GC, Qato DM. Ensuring access to medications in the US during the COVID-19 pandemic. JAMA. April 9, 2020. Online ahead of print. Available at: https://jamanetwork.com/journals/jama/fullarticle/2764562. Accessed June 10, 2020.

5. AMCP. AMCP signs pharmaceutical supply chain stakeholder letter. March 26, 2020. Available at: https://www.amcp.org/policy-advocacy/ letters-statements-analysis/AMCP-Signs-Pharmaceutical-Supply-ChainStakeholder-Letter. Accessed June 10, 2020

6. McLaughlin M, Kotis D, Thomson K, et al. Effects on patient care caused by drug shortages: a survey. J Manag Care Pharm. 2013;19(9):783-88. Available at: https://www.jmcp.org/doi/10.18553/jmcp.2013.19.9.783.

7. U.S. Food and Drug Administratrion. Food and Drug Administration Safety and Innovation Act (FDASIA). July 2012. Available at: https://www. fda.gov/regulatory-information/selected-amendments-fdc-act/food-and-drugadministration-safety-and-innovation-act-fdasia. Accessed June 10, 2020.

8. U.S. Senate Committee on Homeland Security \& Governmental Affairs. A price too high: cost, supply, and security threats to affordable prescription drugs. Available at: https://www.hsgac.senate.gov/imo/media/doc/191206_ Report_APriceTooHigh_ExecutiveSummary.pdf. Accessed June 10, 2020.

9. Silverman E. A new COVID-19 problem: shortages of medicines needed for placing patients on ventilators. STAT. March 31, 2020. Available at: https://www.statnews.com/pharmalot/2020/03/31/a-new-covid-19-problemshortages-of-medicines-needed-for-placing-patients-on-ventilators/. Accessed June 10, 2020

10. Kass NE. An ethics framework for public health. Am J Public Health. 2001; 91(11): 1776-82. 
11. Emanuel EJ, Persad G, Upshur R, et al. Fair allocation of scarce medical resources in the time of Covid-19. N Engl J Med. 2020;382(21):2049-55.

12. Mazer-Amirshahi M, Goyal M, Umar SA, et al. U.S. drug shortages for medications used in adult critical care (2001-2016). J Crit Care. 2017;41:283-88.

13. Unguru Y, Fernandez CV, Bernhardt B, et al. An ethical framework for allocating scarce life-saving chemotherapy and supportive care drugs for childhood cancer. J Natl Cancer Inst. 2016;108(6):djv392.

14. Rosoff PM, Patel KR, Scates A, Rhea G, Bush PW, Govert JA. Coping with critical drug shortages: an ethical approach for allocating scarce resources in hospitals. Arch Intern Med. 2012;172(19):1494-99.
15. Kaakeh R, Sweet BV, Reilly C, et al. Impact of drug shortages on U.S. health systems. Am J Health Syst Pharm. 2011;68(19):1811-19.

16. U.S. Food and Drug Administration. FDA drug shortages. Available at: https://www.accessdata.fda.gov/scripts/drugshortages/default.cfm. Accessed June 10, 2020

17. American Society of Health-System Pharmacists. Current drug shortages. Available at: https://www.ashp.org/Drug-Shortages/Current-Shortages. Accessed June 10, 2020.

18. Mehta B, Salmon J, Ibrahim S. Potential shortages of hydroxychloroquine for patients with lupus during the coronavirus disease 2019 pandemic. JAMA Health Forum. April 10, 2020. Available at: https://jamanetwork.com/ channels/health-forum/fullarticle/2764607. Accessed June 10, 2020. 